\title{
A Correlative Study of Biochemical, Virological \& Histological Parameters of HBV Infection in HIV/HBV Co-Infection
}

\author{
Authors \\ S K Singh ${ }^{1}$, Sarvinder Singh ${ }^{2}$, Bhaskar Shahbabu ${ }^{3}$, Vani Singh ${ }^{4}$ \\ ${ }^{1}$ Lt Col. (Medical Specialist), Military Hospital Namkum, India \\ ${ }^{2}$ Col. Senior Advisor (Medicine and Respiratory Medicine), Military Hospital Namkum, India \\ ${ }^{3}$ Capt. Medical Officer (PSM) \\ ${ }^{4}$ Senior Resident (Dept. of Radiotherapy), RIMS, Ranchi, India
}

\begin{abstract}
Introduction: In the setting of HBV-HIV coinfections, serial monitoring of ALT alone may not predict the severity of $H B V$ disease. This study aims at studying the correlation between ALT, Viral load and the histological progression of $H B V$ related infection in HIV positive individuals.

Methods: The study included 30 ART nä̈ve patients with HIV-HBV co-infection as cases and 30 incidentally detected mono infected (HBsAg positive) as control. All the patients had undergone viral serology, CD4 count and HBV DNA viral load. Selected patients based on HBeAg and HBV-DNA level were subjected to liver biopsy. Liver biopsy was scored by applying Knodell criteria [HAI].

Results-The sero-prevalence rate of HBV in HIV population in our study was $13.3 \%$. HBeAg positivity is 10.7 times (95\% CI: 2.1-53.3) more among the cases than the controls and it was statistically significant. The median ALT level in cases was 34.5 IU/L while in control group it was 77.0 IU/L. The median HBV DNA level in cases was $5.7 \times 105$ copies $/ \mathrm{ml}$ while in control group, it was $7.3 \times 103$ copies $/ \mathrm{ml}$. The number of patients qualified for need of liver biopsy based on HBeAg positivity and HBV DNA levels were 13 in cases and 5 among controls. The median HAI score in cases was 7.0, which was significantly more than among controls.

Conclusion: Treatment modality should be devised based on HBV plasma viral load, HBeAg status and liver biopsy and not based solely upon ALT.

Keywords: HBV-HIV Coinfection. Knodell's Criteria, Liver biopsy score, Histologic Activity Index, HBV plasma viral load, ALT monitoring.
\end{abstract}

\section{Introduction}

AIDS is one of the most devastating pandemics in the history based on its worldwide scope and lethality. It has now been some 33 years since the initial description of AIDS. Following these observations, the epidemiology, natural history and manifestations of this disease have been well characterized. The hepatitis B virus is one of the most common human pathogens worldwide. Primary HBV infection leads to chronic hepatitis in
$2-5 \%$ of immunocompetent adults, whereas HIV infected patients experience chronicity about five times more often ${ }^{[1]}$. A possible reason for this is the HIV associated Tcell defect. A polarization to a Th2-type response could result in the inhibition of specific cellular defense mechanisms (e.g cytotoxicity, production of interferon-Y and interlukin-2, and the T-cell proliferation rate). Hepatitis B and HIV have several common features, although hepatitis B is a double stranded DNA virus. 
After entering the hepatocyte, viral DNA is integrated into the host genome. Viral RNA is translated by $\mathrm{HBV}$ reverse polymerase into new viral DNA and transcribed into viral proteins, in addition to increasing mortality, HIV coinfection accelerates the progression of hepatitis B and increases the risk of cirrhosis. Initially the clinical course is usually more benign in HIV-positive patients, although viral replication is increased. This seems contradictory at first, but can be explained by the impairment of cellular immunity, which may lead to an increase in viral replication, but at the same time also reduces hepatocyte damage ${ }^{[2]}$. Therefore, transaminases in HBV/HIV-coinfected patients are frequently only mildly increased. In contrast, HBV DNA, as a marker for viral replication, shows far greater rise in HIV positive patient as compared to HIV negative cases ${ }^{[2]}$. It should be noted that liver biopsy done in HBV/HIV coinfection might also underestimate the degree of hepatocyte damage. Researchers at Johns Hopkins ${ }^{[3]}$ found that men infected with a combination of hepatitis B and HIV are 17 times more likely to die than those with hepatitis $B$ alone. The time incidence of chronic viral hepatitis diagnosed by biopsy may have been greatly underestimate because most patient with liver abnormalities and positive virus serology would not have had biopsies. Liver biopsy can give useful prognostic information. Among human immunodeficiency virus infected individuals, the prevalence of hepatitis B surface antigen (HBsAg) sero-positivity is 10 fold higher than in general population. HIV-Hepatitis B (HBV) -coinfected patients have an increased risk of cirrhosis and liver disease-related death ${ }^{[3]}$. In the setting of HBV/HIV coinfections, serial monitoring of ALT alone may deny the severity of HBV disease and it is possible that virological load and histology may indicate the true state of affairs and hence the need for treating HBV infections.

This study aims at studying the correlation between biochemical markers, Virological load and the histological progression of HBV related infection in HIV positive individuals with reference to CD4 counts and plasma viral load.

\section{Methodology}

The study was conducted in an ART Centre of a large teaching \& tertiary care hospital from May 2014 to April 2015. In the ART Centre the freshly registered HIV cases that were not yet started on ART were subjected to serological tests like $\mathrm{HBsAg}$, $\mathrm{HBe} \mathrm{Ag}$, anti HBe, Anti HCV, IgM HAV and IgM HEV. Those who were positive for only Hep B were selected as cases. From the lab register the list of incidentally detected Hep B positive patients were taken as control. Considering the time and feasibility, it was decided to take 30 samples of each cases \& controls for the study.

\section{Exclusion Criteria}

- HCV coinfected

- Ac viral hepatitis $\mathrm{A} / \mathrm{E}$

- Drug induced hepatitis

- Known alcoholics

CD4 count was done in all HIV-HBV co-infection cases by flow cytometry.

All patient had undergone were subjected to HBV plasma viral load quantitative analysis. HBV Plasma viral DNA load was done by Geno-sens Real Time Polymerase Chain Reaction Rotorgenekit in all cases. The lowest limit of detection by this method is 600 copies $/ \mathrm{ml}$.

The following patients were subjected to liver biopsy-

a) Patient with $\mathrm{HBeAg}$ positivity and $\mathrm{HBV}$ DNA > 105 copies/ml

b) Patient with $\mathrm{HBeAg}$ negativity and $\mathrm{HBV}$ DNA $<104$ copies/ml.

All the cases of Liver biopsies were subjected to Histological grading. Liver biopsies were scored by applying ISHAK'SKNODELL Criteria [Histologic Activity Index].

Statistical Analysis: Data was collected and entered in MS Excel 2007 and the analysis was done in $\mathrm{R}$ for Windows (3.2.0) using $\mathrm{R}$ studio $\mathrm{V}$ 0.99 . The age distribution of the study participants in both cases and control were categorized and also independent sample $\mathrm{t}$ - test was done to show the difference in the age structure of the two groups. Odds ratio with $95 \%$ CI was calculated to show the 
probability of $\mathrm{HBe} \mathrm{Ag}$ positivity among the case. HBV plasma viral load, ALT level and HAI score among the cases and controls were differentiated using Mann Whitney $U$ test (to compare median between two groups). A Spearman Rho Correlation matrix has been done to show co-relation between ALT level, HBV DNA and HAI score among both cases and controls. $\mathrm{P}$ value of less than 0.05 has been considered as level of statistical significance.

\section{Results}

400 patients who were freshly registered HIV cases were screened and 30 Cases were found to have HIV-HBV coinfection giving a seroprevalence rate of $13.3 \%$. The Mean age of the patients in both cases and control groups were $36.7( \pm 9.1)$ and $36.7( \pm 8.5)$ respectively and there was no statistically significant difference $(p=0.31)$ between the two group (Table 1). The mean CD4count of the HIV-HBV coinfected patients (cases) was $336.7( \pm 126.7)$. HBe Ag positivity is 10.7 times (95\% CI: 2.1-53.3) more among the cases than the controls and it is statistically significant (Table 2). The median value of HBV plasma viral load was more among the cases than the control and it was statistically significant but the ALT level was more among the controls (Table 3). The median HAI score was 7.0 among cases while among the controls it was 4.0 and the difference was also statistically significant (Table 4). Table 5 shows the correlation between ALT level, HBV DNA, and HAI (Histologic Activity Index) score among the cases and controls. No significant correlation exists between the variables in either cases or control group.

Table 1 Distribution of study participants according to their age

\begin{tabular}{|l|c|c|c|c|}
\hline $\begin{array}{l}\text { Age group } \\
\text { (in yrs.) }\end{array}$ & $\begin{array}{c}\text { Control } \\
(\mathrm{n}=30) \\
\text { No }(\%)\end{array}$ & $\begin{array}{c}\text { Cases } \\
(\mathrm{n}=30) \\
\text { No }(\%)\end{array}$ & $\begin{array}{c}\text { Total } \\
\text { No. }(\%)\end{array}$ & p-value \# \\
\hline$<30$ & $5(16.7)$ & $6(20.0)$ & $11(18.3)$ & \\
\hline $30-39$ & $10(33.3)$ & $13(43.3)$ & $23(38.3)$ & \multirow{2}{*}{-} \\
\hline $40-49$ & $13(43.3)$ & $7(23.3)$ & $20(33.3)$ & \\
\hline$\geq 50$ & $2(6.7)$ & $4(13.3)$ & $6(10.0)$ & \\
\hline Total & $30(100.0)$ & $30(100.0)$ & $60(100.0)$ & \multirow{2}{*}{0.31} \\
\hline Mean (SD) & $39.1(9.1)$ & $36.7(8.5)$ & - & \\
\hline
\end{tabular}

\# Independent sample t test.
Table 2 Distribution of study participants according to their $\mathrm{HBe} \mathrm{Ag}$ positivity

\begin{tabular}{|l|c|c|c|c|}
\hline HBe Ag & $\begin{array}{c}\text { Control } \\
(\mathrm{n}=30) \\
\text { No }(\%)\end{array}$ & $\begin{array}{c}\text { Cases } \\
(\mathrm{n}=30) \\
\text { No }(\%)\end{array}$ & $\begin{array}{c}\text { Total } \\
\text { No }(\%)\end{array}$ & $\begin{array}{c}\text { OR } \\
(95 \% \mathrm{CI})\end{array}$ \\
\hline Negative & $13(43.3)$ & $17(56.7)$ & $30(100.0)$ & Ref. \\
\hline Positive & $2(6.7)$ & $28(93.3)$ & $30(100.0)$ & $\begin{array}{c}10.7 * \\
(2.1-53.3)\end{array}$ \\
\hline
\end{tabular}

Table 3 HBV plasma viral load and ALT level among the cases and control.

\begin{tabular}{l|c|c|c|}
\hline & $\begin{array}{c}\text { Control } \\
(\mathrm{n}=30) \\
\text { Median (IQR) }\end{array}$ & $\begin{array}{c}\text { Case } \\
(\mathrm{n}=30) \\
\text { Median (IQR) }\end{array}$ & p-value \# \\
\hline $\begin{array}{l}\text { HBV plasma viral } \\
\text { load (copies/ml) }\end{array}$ & $\begin{array}{c}7.3 \times 103 \\
(4.5 \times 103-7.8 \times 104)\end{array}$ & $\begin{array}{c}5.7 \times 105 \\
(1.7 \times 104-4.7 \times 106)\end{array}$ & $0.02 *$ \\
\hline ALT level (IU/L) & $77(63-106.5)$ & $34.5(22.75-42.75)$ & $<0.001^{* *}$ \\
\hline
\end{tabular}

Table 4: HAI Score among the cases and controls:

\begin{tabular}{|l|c|c|c|c|}
\hline & \multicolumn{3}{|c|}{ HAI Score } & \multirow{2}{*}{-vaue \# } \\
\cline { 1 - 4 } & Minimum & Maximum & $\begin{array}{c}\text { Median } \\
(\mathrm{IQR})\end{array}$ & \\
\hline Control $(\mathrm{n}=5)$ & 3 & 5 & $4.0(3.5-5.0)$ & \multirow{2}{*}{$0.01^{*}$} \\
\hline Case $(\mathrm{n}=13)$ & 1 & 12 & $7.0(7.0-8.5)$ & \\
\hline
\end{tabular}

\# Mann Whitney U test of significance

* Significant at the level of $99 \%$

Table 5: Correlation matrix showing correlation between ALT level, HBV DNA and HAI score among cases and control group:

\begin{tabular}{|l|l|c|c|c|c|c|c|}
\hline \multicolumn{2}{|c|}{} & \multicolumn{2}{|c|}{ ALT LEVEL } & \multicolumn{2}{c|}{ HBV DNA } & \multicolumn{2}{c|}{ HAI SCORE } \\
\hline & & Control & Case & Control & Case & Control & Case \\
\hline \multirow{4}{*}{ ALT } & $\begin{array}{l}\text { Spearma } \\
\text { n Rho }\end{array}$ & 1 & 1 & .135 & -0.042 & -0.580 & -0.171 \\
\cline { 2 - 8 } & p-value & & & .478 & 0.827 & 0.306 & -0.577 \\
\cline { 2 - 8 } & $\mathrm{N}$ & 30 & 30 & 30 & 30 & 5 & 13 \\
\hline \multirow{4}{*}{$\begin{array}{l}\text { HBV } \\
\text { DNA }\end{array}$} & $\begin{array}{l}\text { Spearma } \\
\text { n Rho }\end{array}$ & .135 & -0.042 & 1 & 1 & -0.264 & 0.267 \\
\cline { 2 - 8 } & p-value & .478 & 0.827 & & & 0.668 & 0.377 \\
\cline { 2 - 8 } & $\mathrm{N}$ & 30 & 30 & 30 & 30 & 5 & 13 \\
\hline \multirow{3}{*}{$\begin{array}{l}\text { HAI } \\
\text { SCOR } \\
\text { E }\end{array}$} & $\begin{array}{l}\text { Spearma } \\
\text { n Rho }\end{array}$ & -0.580 & -0.171 & -0.264 & 0.267 & 1 & 1 \\
\cline { 2 - 8 } & $\mathrm{p}$-value & 0.306 & -0.577 & 0.668 & 0.377 & & \\
\cline { 2 - 8 } & $\mathrm{N}$ & 5 & 13 & 5 & 13 & 5 & 13 \\
\hline
\end{tabular}

\section{Discussion}

All the 60 patients $30 \mathrm{HIV}-\mathrm{HBV}$ co infected and 30 incidentally detected HBV mono infected patients were males. All these 60 individual were population of serving soldiers of the study population. Maximum number of patients was in 30-49 yrs. age group $^{[4]}$. The literature also suggests that the majority of the co-infective patients are in the similar age group. It appears unlikely the sex would have any difference in the study parameters however sex distribution would be desirable for 
better generalizability and hence need for a longer and even sex distribution study in future.

The sero-prevalence rate of HBV in HIV in our study was $13.3 \%$. A retrospective analysis ${ }^{[5]}$ was performed on laboratory data from 837 HIV seroreactive patients at AIIMS, New Delhi who were tested in their laboratory from January 2002 to December 2007. Overall, HBsAg positivity (HBV co-infection) was seen in 61 HIV positive patients $(7.3 \%)$. Worldwide it is estimated that $10 \%$ of the 40 million HIV-infected individuals have chronic hepatitis B.

\section{HBeAg positivity}

28 individuals were $\mathrm{HBeAg}$ positive in co-infected group while 17 were $\mathrm{HBeAg}$ positive in incidentally detected HBV mono infected patient. In our study 2 patients were Anti Hbe positive HIV-HBE coinfected group while 13 were in incidentally detected HBV monoinfected group. Observations of increased $\mathrm{HBV}$ replication and lower rates of $\mathrm{HBeAg}$ seroconversion in HIV/HBV co-infected patients, compared to patients with incidentally detected monoinfected group, suggest that HBV infection is replicating more in the case of dual infection. Our study further shows that HIV infection also decreases the rate of hepatitis $\mathrm{B}$ e antigen $(\mathrm{HBeAg})$ clearance. A retrospective study by Bodsworth et al ${ }^{[6]}$ found decrease rate of $\mathrm{HBeAg}$ clearance upto 5 fold and increase in the level of $\mathrm{HBV}$ replication as manifested by higher $\mathrm{HBV}$ DNA levels.

\section{ALT Levels}

The median ALT level in HIV-HBV co-infected patient was 34.5 (IQR 22.7-42.7) while in incidentally detected HBV mono infected patients it was 77 (IQR 63-106.5). Our study shows normal ALT level in HIV-HBV co-infected individual despite of high HBV plasma viral load. Our study also shows that median ALT was higher in incidentally detected HBV mono infected group compared to co-infected group.

\section{HBV Plasma Viral Load}

In our study, HBV plasma viral load was done by Genosens Real Time Polymerase Chain Reaction Rotorgenekit in all patients in both groups. The median HBV DNA level in HIV-HBV co-infected patients was $5.7 \times 105$ copies $/ \mathrm{ml}$ while in incidentally detected mono infected group, it was $7.3 \times 103$ copies/ml (approx). Higher HBV viral levels have been consistently associated with poorer clinical outcomes, particularly when the levels of $\mathrm{HBV}$ DNA were above 105 copies/ml relative to very low or undetectable levels. However, having low or undetectable DNA did not eliminate the risk of clinical outcomes. Furthermore, much less is known about the extent to which spontaneous or druginduced reductions in viral lead to improvements in clinical outcomes. The Taiwan REVEAL-HBV (Risk Evaluation of Viral Load Elevation and Associated Liver Disease/Cancer HBV) study [7] found that in multivariable models adjusted for age, sex smoking, alcohol use, HBeAg status, ALT level, and cirrhosis, the risk of HCC increased slightly for people with >104 copies $/ \mathrm{ml}$ and sick was approximately six times higher for people with viral levels above 105 as compared to those with undetectable viral levels. This same study ${ }^{[7]}$ reported a similar association between viral level and risk of cirrhosis. Additional reports from this study have also shown a large increase in rate of liver- related mortality and a modest (approximately two - fold) increase in all -cause mortality in people with HVA DNA levels >105 compared to those with levels $<105$ copies $/ \mathrm{ml}$. There was no significant increase in risk of death from causes unrelated to the liver in those with elevated HBA DNA level ${ }^{[8]}$. Our study showed that HBA DNA levels are higher in HIV infected patients than in subject with $\mathrm{HBV}$ alone. A few cross-sectional studies ${ }^{[8]}$ that examined the association of active liver inflammation and fibrosis and HBV DNA level found that approximately $90 \%$ of those with active liver disease at the time of liver biopsy who are $\mathrm{HBeAG}$ negative and have an elevated ALT have an HBA DNA level of $>105$ genomic copies/ml $(20,000 \mathrm{IU} / \mathrm{mL})$, and $1 \%$ have levels between 104 copies/ml. However, many persons in these studies ${ }^{[8]}$ with HBV DNA levels 
above 104 or even 105 copies/ml have minimal or no inflammation on biopsy. Thus, while HBA DNA > $2000 \mathrm{IU} / \mathrm{mL}$ appears to be a reasonable level at which to evaluate persons with chronic HBV infection for the extent of liver disease, a liver biopsy may be necessary to identify those with the significant findings of moderate or severe inflammation and fibrosis.

\section{Liver Biopsy \& Biopsy Score}

The number of patients qualified for need of liver biopsy based on HBeAg positive and HBV DNA levels were 13 in HIV-HBV co-infected and 5 in incidentally detected HBV mono-infected individual. The median HAI (Histolgy Activity Index) scores in HIV-HBV co-infected group 7.0 (IQR 7.0-8.5) while in incidentally detected HBV mono-infected group was 4.0 (IQR 3.5-5.0).

The median HBV DNA level in patients who underwent liver biopsy was 4.7 x 106 copies/ml. Their corresponding HAI score was 7.0. This shows that HAI score was more in patients with high plasma viral load. Our study shows low ALT level in co-infected individual despite of having high HBV plasma viral load.

Out of 13 patients who were subjected to liver biopsy 11 of them had HAI scoring $>3$. This indicates that in the setting of HBV viral load of $>105$ copies/ml there was significant necroinflammation in the liver despite ALT being normal.

It is recommended that liver biopsy should be done even if ALT is normal based on HBV plasma viral load. In a cross-sectional study of 55 patientswho were $\mathrm{HBeAG}$-Negative with chronic hepatitis B, patients with detectable HBV DNA levels ( $>0.5$ $\mathrm{mE} / \mathrm{Ml}$ ) had significantly higher necroinflammation scores in histology actively index (HAI) than those with undetectable HBV DNA levels ${ }^{[9]}$.

\section{CD4 Count}

The mean CD4 count in HIV - HBV co-infected group was 336.16 cell/ul. 21 patients in our study had CD4 counts >300 Cell/UI. The mean CD4 count of HIV HBV co-infected patient who underwent biopsy was 316.12 . In our study majority of patient had CD4 count $>300$ cell/UI therefore had relatively preserved immune function. The HAI score of the patients in the co-infected group who underwent liver biopsy was 7.0, which means that despite having a well preserved CD4 count, the necro-inflammatory score were substantial and do merit treatment of HBV infection with antiviral. It is also to be noted that the ALT would have been misleading as regards of therapeutic decision since the median value of ALT was 34.5 IU/L in HIVHBV coinfected group.

\section{References}

1. McGovern BH. The epidemiology, natural history and prevention of hepatitis B: implications of HIV co-infection. Antivir Ther 2007; 12(Suppl 3): H3-H13.

2. Alter MJ. Epidemiology of viral hepatitis and HIV co-infection. J Hepatol 2006; 44(1 Suppl ): S6-S9.

3. PalellaFJJr, Baker RK, Moorman AC, ChmielJS, Wood KC, Brooks JT, et al. Mortality in the highly active antiretroviral therapy era: changing causes of death and disease in the HIV outpatient study. J Acquir Immune DeficSyndr 2006; 43: 27-34.

4. Liang, T. Jake, and Marc Ghany. "Hepatitis B E Antigen - The Dangerous Endgame Of Hepatitis B". New England Journal of Medicine 347.3 (2002): 208-210. Web.

5. Gupta, Swati, and Sarman Singh. "Occult Hepatitis B Virus Infection In ART-Naive HIV-Infected Patients Seen At A Tertiary Care Centre In North India". BMC Infectious Diseases 10.1 (2010).

6. Bodsworth NJ, Cooper DA, Donovan B. The influence of human immunodeficiency virus type 1 infection on the development of the hepatitis B carrier state. J Infect Dis 1991; 163: $1138-1140$

7. Chen, Chien-Jen, Uchenna H. Iloeje, and Hwai-I. Yang. "Long-Term Outcomes In Hepatitis B: The REVEAL-HBV Study". Clinics in Liver Disease 11.4 (2007): 797816.

8. Chan, H. "Viral Genotype And Hepatitis B Virus DNA Levels Are Correlated With 
Histological Liver Damage In HbeagNegative Chronic Hepatitis B Virus Infection". The American Journal of Gastroenterology 97.2 (2002): 406-412. Web.

9. Nabuco, Leticia Cancella et al. "HBV-DNA Levels In Hbsag-Positive Blood Donors And Its Relationship With Liver Histology". Journal of Clinical Gastroenterology 41.2 (2007): 194-198. Web. 